\title{
"DONA DESSA BELEZA": EMPODERAMENTO FEMININO, CORPOS DIFERENTES E INCLUSÃO NO DISCURSO PUBLICITÁRIO DA AVON
}

\author{
"She owns this beauty": female empowerment, different \\ bodies, and inclusion in the Avon advertising discourse \\ "Dueña de esta belleza": empoderamiento femenino, cuerpos \\ diferentes e inclusión en el discurso publicitario de Avon
}

\author{
Leonardo Mozdzenski \\ Universidade Federal do Pernambuco, Pernambuco, Brasil. \\ Doutor em Linguística pelo Programa de Pós-Graduação em Letras da Universidade Federal do Pernam- \\ buco (UFPE), doutorando em Comunicação pelo Programa de Pós-Graduação em Comunicação da UFPE. \\ Integrante do Grupo de Pesquisa As narrativas da publicidade híbrida e os novos papéis do consumidor, \\ coordenado pelo prof. dr. Rogério Covaleski. \\ E-mail: leo_moz@yahoo.com.br
}

\section{Keliny Cláudia da Silva}

Universidade Federal do Pernambuco, Pernambuco, Brasil.

Mestre em Comunicação pelo Programa de Pós-Graduação em Comunicação da Universidade Federal do Pernambuco. Integrante do Grupo de Pesquisa As narrativas da publicidade híbrida e os novos papéis do consumidor, coordenado pelo prof. dr. Rogério Covaleski.

E-mail: kelinyclaudia@gmail.com

\section{Liliana Barros Tavares}

COM acessibilidade comunicacional, Pernambuco, Brasil.

Doutoranda em Comunicação pelo Programa de Pós-Graduação em Comunicação da Universidade Federal do Pernambuco. Audiodescritora e Gestora da COM acessibilidade comunicacional (Recife/PE).

E-mail: comacessibilidade@gmail.com

RESUMO Nesta pesquisa, objetivamos investigar os "discursos da diferença” que emergem no domínio publicitário e trazem representações de corpos diferentes. Para tanto, adotamos os princípios da Análise Crítica do Discurso para examinar a campanha publicitária "Dona dessa beleza”, da Avon, protagonizada por corpos não hegemônicos - negros, transexuais, plus size e com deficiências -, e que também se encontra disponível em uma versão com acessibilidade. As discussões teóricas sobre o empoderamento feminino, o corpo não normativo e a inclusão social baseiam-se em Fairclough, McRobbie, Hoff, León, entre outros.

PALAVRAS-CHAVE Publicidade, Empoderamento feminino, Corpos diferentes, Inclusão, Beleza.

ABSTRACT In this research we aim to investigate the "discourses of difference" that emerge in the advertising realm and bring representations of different bodies. To do so, we have adopted the principles of Critical Discourse Analysis to examine Avon's advertising campaign "She owns this beauty", featuring non-hegemonic bodies - black, transsexual, plus size, and disabled and which is also available in a version with accessibility. The theoretical discussions on female empowerment, non-normative body, and social inclusion are based on Fairclough, McRobbie, Hoff, León, among others.

KEYWORDS Advertising, Female empowerment, Different bodies, Inclusion, Beauty. 
RESUMEN En este estudio, pretendemos investigar los "discursos de la diferencia" que surgen en el campo publicitario y aportan representaciones de diferentes cuerpos. Para ello, hemos adoptado los principios del Análisis Crítico del Discurso para examinar la publicidad de Avon "Dueña de esta belleza”, con cuerpos no hegemónicos - negro, transexual, p/us size y discapacitados-y que también está disponible en una versión con accesibilidad. Las discusiones teóricas sobre el empoderamiento femenino, el cuerpo no normativo y la inclusión social se basan en Fairclough, McRobbie, Hoff, León, entre otros.

PALABRAS CLAVE Publicidad, Empoderamiento femenino, Cuerpos diferentes, Inclusión, Belleza.

\section{DING DONG, AVON CHAMA: DE BRINDE A SUCESSO DE VENDAS}

A beleza é a jornada, o empoderamento é o destino. Slogan da Avon norte-americana ${ }^{1}$

Eram os anos 1960 e, aqui no Brasil, a cena começava a ficar cada vez mais frequente. Donas de casa da classe média recebiam periodicamente em suas residências as promotoras de venda de cosméticos de uma empresa norte-americana com crescente penetração em nossos lares. A Avon comercializava perfumes, xampus, cremes rinses, sabonetes, bálsamos, loções e hidratantes corporais - tudo vendido de porta em porta por sorridentes e bem arrumadas representantes, com perfil não muito diferente de suas clientes. A fórmula foi um sucesso.

O clássico slogan "Ding Dong, Avon chama” (originalmente, "Ding Dong, Avon calls") captava exatamente esse "momento mágico” em que os produtos da Avon chegavam a milhares de domicílios pelas mãos do “amável serviço pessoal da Revendedora Avon”, com promessas de beleza e deleites aromáticos (Figura 1). O jingle divulgado nas rádios nos anos 1970 também seguia esse mesmo mote:

Ding Dong, Ding Dong, Avon chama!

Dê as boas-vindas à sua revendedora Avon (Avon!)

Ela tem pra você sugestivas fragrâncias

Para a sua intuição feminina escolher

[Voz em off] Avon, fragrâncias maravilhosas!

Experimente-as antes de comprar, no conforto do lar, com a ajuda de sua revendedora Avon.

[Som de campainha] Avon chama! (AVON... 2016)

Essa bem-sucedida estratégia de venda direta de cosméticos foi, no entanto, fruto do acaso. Como revela o site da empresa ${ }^{2}$, tudo começou com um "quase fracasso". David Hall McConnell - então um vendedor de livros e enciclopédias em Nova York, com 28 anos de idade - teve uma engenhosa ideia para que seus compradores em potencial não lhe batessem a porta na cara. Ele passou a oferecer como brinde um vidro de perfume para os clientes que concordassem em ouvir sua apresentação até o final.

1. Disponível em: <https://goo.gl/2KaV3T>. Acesso em: 19 nov. 2016.

2. Disponível em: <https://goo.gl/PkG8g>. Acesso em: 24 nov. 2016. 

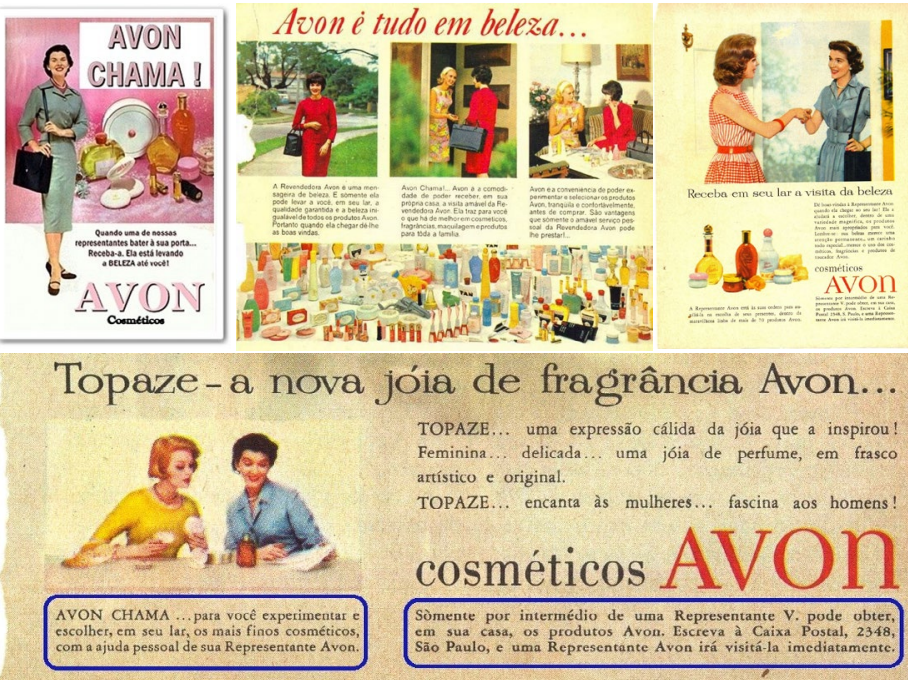

Figura 1. Anúncios antigos dos produtos Avon em revistas femininas brasileiras (anos 1960). Fonte: Blog Anos Dourados3.

McConnell começou a notar, entretanto, que os perfumes acabavam despertando uma reação bem mais positiva que livros ou enciclopédias. E assim, em 1886, é fundada a empresa California Perfume Company (CPC), especializada na venda em domicílio de fragrâncias como rosa branca, violeta, lírio, jacinto e heliotrópio. O próprio David McConnell criava os perfumes e concomitantemente desempenhava as funções de contador, despachante e office boy. Para auxiliá-lo na distribuição, o empresário convocou uma amiga, Persis Foster Eames Albee, uma viúva de 50 anos, para ser a primeira revendedora dos seus perfumes.

Miss Albee - como ficou posteriormente conhecida - não economizava esforços na divulgação dos produtos, percorrendo inúmeras cidades norte-americanas de trem ou mesmo a cavalo. Foi ela quem de fato estabeleceu e disseminou a marca em todo território ianque. Em menos de dez anos, Albee havia conseguido recrutar cerca de 25 mil mulheres para revender seus cosméticos. E com isso, a CPC tornou-se diretamente responsável por instituir um novo papel para as mulheres na sociedade e na economia do país.

Nunca é demais relembrar que, até então, a única ocupação socialmente aceitável para a mulher era ser dona de casa. Vale salientar, inclusive, que as mulheres sequer possuíam direito a voto naquela época - o que só viria a ocorrer em 1920. Dessa maneira, Miss Albee e suas "discípulas" tornam-se referências importantes sobre o novo modelo feminino de comportamento da "mulher moderna", motivando-a a exercer uma atividade comercial autônoma e independente de seus maridos.

O nome Avon só surge mesmo em 1939, inspirado na cidade de Stratford-upon-Avon, on1e nasceu o escritor inglês William Shakespeare, de quem McConnell era admirador. A partir dos anos 1950, a Avon decide ampliar seus negócios para o mercado internacional e rapidamente obtém uma grande aceitação do público feminino nos cinco continentes. Em 1972, as vendas da empresa conseguem alcançar pela primeira vez o montante de 1 bilhão de dólares, com aproximadamente 600 mil revendedoras da

3. Disponível em: <https://goo.gl/VJ5Iax>. Acesso em: 23 nov. 2016. 
marca. No final da década de 1970, é ultrapassada a marca de 2 bilhões de dólares em vendas, e as revendedoras dos produtos Avon totalizam, então, em torno de 1 milhão de mulheres ao redor do mundo.

Nas décadas seguintes, a Avon passa a diversificar seu portfólio, comercializando de bijuterias a relógios, de roupas a artigos para a casa, de livros a produtos infantis. E, de modo pioneiro na indústria dos cosméticos, em 1996 a empresa dá início à venda de suas mercadorias pela internet. O crescente sucesso da Avon, no entanto, não se deu apenas na esfera mercadológica. Cada vez mais, foi sendo possível observar iniciativas e projetos sociais de valorização das mulheres.

Ainda nos anos 1980, por exemplo, teve início a primeira Avon International Women's Marathon, evento que integrava o tradicional International Running Circuit. Essa ação, inclusive, contribuiu de forma decisiva para que a maratona feminina fosse oficializada como esporte olímpico em 1984, nos Jogos de Los Angeles. Além do incentivo às atividades desportivas, outra plataforma bastante cara à Avon é o combate à violência doméstica. Em 2000, foi criada uma campanha global chamada "Let's talk" - tendo à frente as tenistas Venus e Serena Williams - justamente para dar visibilidade a esse assunto. E em 2004, a campanha "Speak out against domestic violence" trouxe a atriz mexicana Salma Hayek como porta-voz da Avon Foundation for Women, rechaçando qualquer atitude no ambiente doméstico que provocasse lesão, morte ou sofrimento físico, psicológico e sexual contra a mulher. ${ }^{4}$

Outra frente em que a Avon é bastante atuante diz respeito ao combate ao câncer de mama, com sua campanha global "Avon breast cancer crusade". Chamada no Brasil de "Avon contra o câncer de mama", essa iniciativa tem como finalidade arrecadar fundos para desenvolver ações que proponham reduzir a mortalidade feminina provocada pela doença, incentivando o diagnóstico precoce e a prevenção. A campanha "Avon breast cancer crusade" é, inclusive, a responsável pela criação, em 1992, do pin com fita rosa, que se tornou um símbolo mundial da causa, sobretudo durante o chamado "Outubro rosa".

Com uma agenda tão voltada para as demandas femininas, não é de surpreender um posicionamento cada vez mais assertivo nas campanhas da Avon acerca da importância do papel da mulher na sociedade. Esse compromisso é reiterado em diversos momentos no site da empresa, como constatamos no seguinte excerto, ressaltando o empoderamento feminino:

A Avon acredita no poder e potencial que a beleza tem para transformar vidas. Nosso conceito de beleza é mais profundo: um caminho para empoderar mulheres, o qual conta com os consumidores de nossos produtos, nossos seis milhões de revendedores, em várias partes do mundo, e nossos mais de 30 mil funcionários, em diversos países, os quais trabalham juntos por esse propósito. Nossos funcionários celebram cada ideia colocada em prática, pois sabem que são agentes de mudança. Assim, colaboram com a missão de transformar o mundo em um lugar melhor para as mulheres e compartilham essa missão. (TRABALHO..., [20??], n.p., grifo no original)

Mas como um conceito sociopolítico tão sofisticado e cheio de nuanças ideológicas como "empoderamento" passou a operar no discurso publicitário da Avon como um influente slogan aparentemente engajado?

4. Disponível em: <https://goo.gl/xuSUZ5>. Acesso em: 26 nov. 2016. 
E mais: como é que, a partir dessa questão, podemos refletir sobre a própria construção identitária da mulher e a representação da beleza feminina na publicidade? É sobre isso que iremos discutir a seguir.

\section{O DISCURSO DO EMPODERAMENTO: UMA ANÁLISE CRÍTICA}

De acordo com Deneulin e Shahani (2009), o termo "empoderamento" (empowerment) é usado nas Ciências Sociais, nos Estudos Culturais, na Economia e na Psicologia, como o processo através do qual os sujeitos, individualmente ou agrupados socialmente, ampliam a capacidade de gerir suas próprias vidas em função do modo como desenvolvem o seu entendimento acerca de suas potencialidades e de sua participação na sociedade. No entanto, mais do que aumentar a autonomia e o poder pessoais, o empoderamento envolve uma tomada de consciência coletiva por grupos minoritários e/ou marginalizados contra a opressão social das elites e a dependência política.

Para entendermos como e por que se dá a transposição de um termo tão significativo quanto "empoderamento" para o discurso publicitário e empresarial da Avon, iremos recorrer aos princípios teórico-metodológicos da Análise Crítica do Discurso (ACD). É importante esclarecermos logo de início que a ACD é aqui compreendida como o estudo das relações dialéticas entre as diversas semioses que compõem qualquer discurso a partir dos processos sociais em que ele está inserido. Ou seja, constituem objeto de investigação da ACD não só textos verbais (orais e escritos), mas também imagens, sons/música, gestos/performances corporais, e assim por diante. Segundo Fairclough (2012, p. 308):

Esta vertente da ACD está baseada em uma visão de semiose como a parte irredutível dos processos sociais materiais. A semiose inclui todas as formas de construção de sentidos - imagens, linguagem corporal e a própria língua. Vemos a vida social como uma rede interconectada de práticas sociais de diversos tipos (econômicas, políticas, culturais, entre outras), todas com um elemento semiótico. A concepção de práticas sociais nos permite combinar as perspectivas de estrutura e de ação - uma prática é, por um lado, uma maneira relativamente permanente de agir na sociedade, determinada por sua posição dentro da rede de práticas estruturada; e, por outro, um domínio de ação social e interação que reproduz estruturas, podendo transformá-las. Todas são práticas de produção, arenas dentro das quais a vida social é produzida, seja ela econômica, política, cultural, ou cotidiana.

Ainda de acordo com Fairclough (2012), as análises realizadas com base nos preceitos da ACD devem levar em conta os seguintes elementos: atividade produtiva, meios de produção, relações sociais, identidades sociais, valores culturais, consciência e as semioses integrantes do discurso. A ACD considera que todos esses elementos se relacionam de forma dialética, uma vez que consistem em noções diferentes, mas não totalmente separadas e distintas. É imprescindível, pois, que esses elementos sejam contemplados globalmente de forma transdisciplinar pelas pesquisas realizadas sob as premissas da ACD.

Dessa maneira, seguindo essa proposta crítica, adotaremos os moldes da "concepção tridimensional do discurso" elaborada por Fairclough (2016). Em sua abordagem, o autor propõe que o discurso seja analisado 
em três níveis distintos, mas intrinsecamente interdependentes, conforme o esquema a seguir (Figura 2):

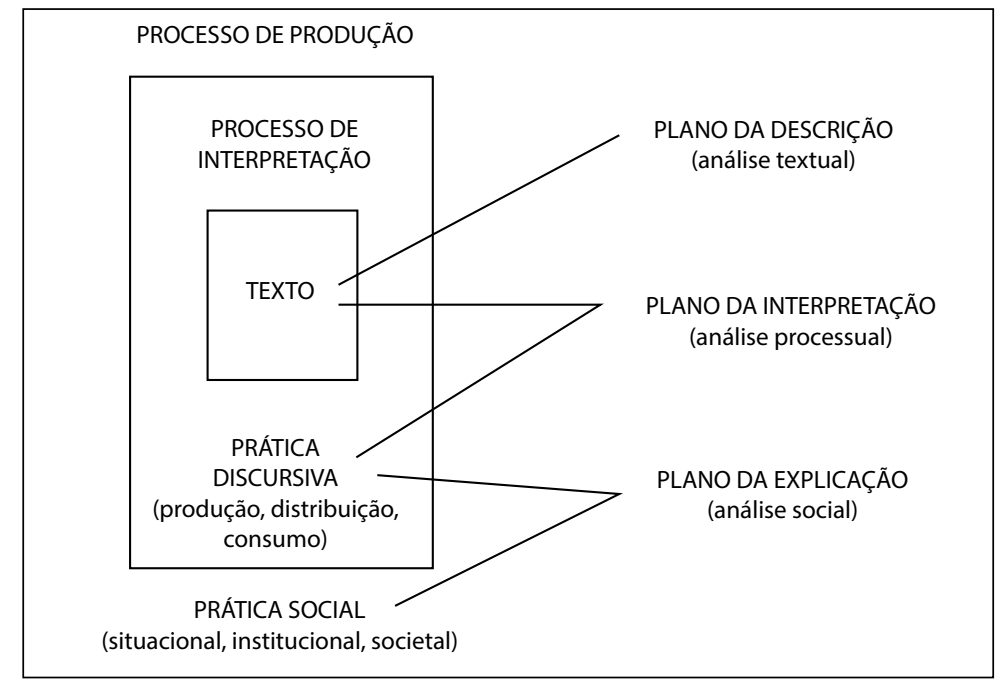

Figura 2. Concepção tridimensional do discurso de Fairclough.

Fonte: Adaptado de Fairclough (2016, p. 105).

Esses três níveis de análise podem ser assim compreendidos:

- a análise dos textos falados e escritos, que se compõe do estudo do vocabulário, da gramática, da coesão e da estrutura textual;

- a análise das práticas discursivas, em que se examina a "força” dos enunciados, isto é, a intertextualidade, a construção de sentidos, a coerência dos textos etc.;

- a análise do discurso como práticas sociais, em que são abordados os contextos culturais, socioeconômicos e ideológicos, enquadrando e moldando os textos e as práticas.

Partindo desses preceitos, podemos agora retomar a interpretação da noção de "empoderamento", tal como vem sendo utilizada nos discursos da Avon. De início, é possível constatar a recorrente associação do termo à independência financeira da mulher (indivíduo, e não grupo social) - a qual, aliás, não é mais chamada revendedora, e sim, eufemisticamente, uma "executiva de vendas" . É o que averiguamos já na própria definição do termo, assim como se encontra expresso no site da empresa: "EM. PO.DE.RA.MEN.TO: É a capacidade do indivíduo realizar, por si mesmo, as mudanças necessárias para evoluir e se fortalecer. Para levar a vida da forma que escolher” (PALAVRAS... [20??], n.p.).

Como advém dessa definição, pode-se concluir que Avon entende o empoderamento como uma ação individual, particular, algo bastante distinto do conceito sociológico do termo, abordado no início desta seção. Isso não é casual ou fortuito. Antes, essa perspectiva integra uma noção mais ampla sobre a "comodificação do feminismo" na contemporaneidade, como defende McRobbie (2004). Consoante a autora, podemos observar hoje em dia a progressiva incorporação das concepções feministas ao ideário capitalista, reconstruindo a identidade da feminista contemporânea. Isto é, "feminista" não representa mais

5. Disponível em: <https://goo.gl/fsB744>. Acesso em: 27 nov. 2016. 
um posicionamento político-ideológico e passa a ser visto meramente como uma opção de consumo e de “estilo de vida”. A noção é confinada à personificação de mulheres bem-sucedidas na sociedade (Figura 3):

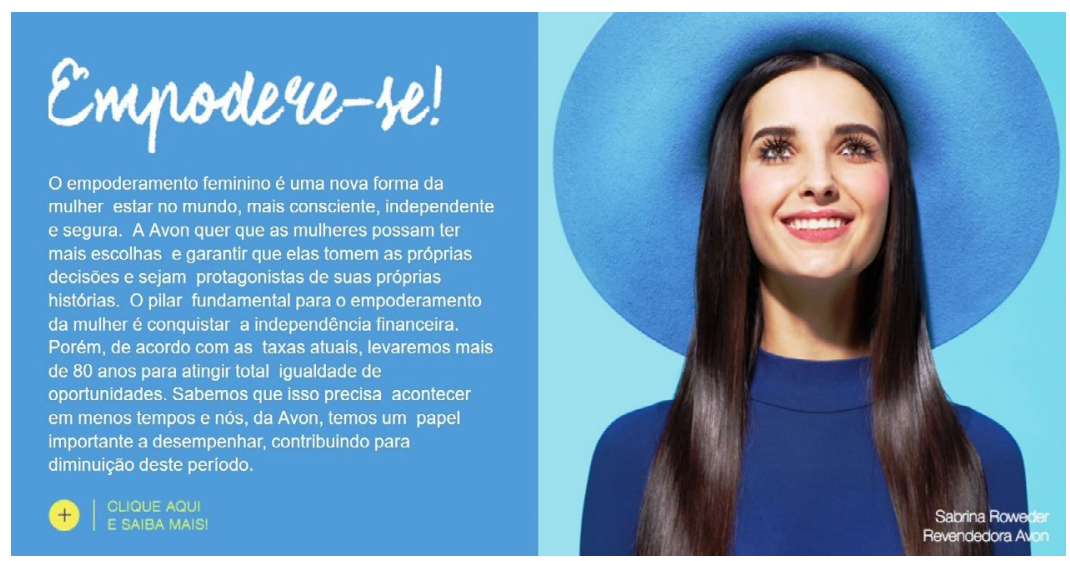

Figura 3 - Site da Avon [detalhe].

Fonte: Avon ${ }^{6}$

McRobbie (2004, p. 257) denomina esse processo como "individualização feminina”. Consiste, em outras palavras, em um fenômeno no qual ocorre a substituição do discurso do engajamento e da militância coletiva pelo discurso das decisões pessoais. A justificativa, por não ser bem-sucedida, é desarticulada do contexto sociocultural e imputada à mulher como indivíduo. Douglas (2002) argumenta que, em decorrência desse ponto de vista, naturaliza-se a ideia de que os obstáculos a serem superados pelas mulheres na tentativa de harmonizar família e trabalho são, na realidade, desafios individuais. Ou seja, devem ser enfrentados e vencidos essencialmente por meio de uma organização particular eficiente, por escolhas pessoais sensatas e com uma postura autoconfiante, sem nenhuma intervenção do fator social.

Isso fica bastante claro no discurso da Avon ao propagar que a empresa "quer que as mulheres possam ter mais escolhas e garantir que elas tomem as próprias decisões e sejam protagonistas de suas próprias histórias" (PALAVRAS... [20??], n.p.), ou ainda que o "pilar fundamental para o empoderamento da mulher é conquistar a independência financeira” (PALAVRAS... [20??], n.p.). Os efeitos de sentidos produzidos a partir da imagem da Revendedora Avon constante na Figura 3 reiteram essa percepção. Trata-se de uma mulher branca, magra, com cabelos lisos e brilhosos, muito bem maquiada, com uma aparência geral de "jovem bem-sucedida". Ela olha para cima com um sorriso largo, como se estivesse vendo/imaginando um futuro radiante à sua frente. A disposição cromática em vários tons de azul e a estruturação plástica do anúncio bastante equilibrada reforçam a noção de estabilidade, harmonia e um certo requinte da composição.

Esse cenário construído pela Avon acerca do empoderamento fomenta o agenciamento feminino individual, a autonomia econômica e o poder de emancipação majoritariamente através do consumo. Constitui um modelo de conquista da independência e da liberdade por meio das preferências de cada mulher, no papel de consumidoras e integrantes do mercado de trabalho. Desse modo, seu "poder de escolha” não está

6. Disponível em: <https://goo.gl/bspS7h>. Acesso em: 28 nov. 2016. 
mais relacionado ao direito ao aborto ou ao controle sobre a reprodução, mas sim ao seu livre-arbítrio na hora de adquirir um novo automóvel ou preferir comprar sapatos e perfumes de uma certa grife.

Tyler (2005, p. 37, tradução nossa) denomina essa postura como "narcisismo como liberação", uma vez que estimula as mulheres "a se autocompensarem em razão da desigualdade sexual e das dificuldades vivenciadas ao tentarem equilibrar as prioridades do trabalho e da maternidade, através do consumo de velas aromáticas e sais de banho". Esse empoderamento promovido pela Avon teria, dessa maneira, pouca ou nenhuma correspondência com o empoderamento tradicionalmente defendido pelas feministas:

Para nós, feministas, o empoderamento de mulheres é o processo da conquista da autonomia, da autodeterminação. E trata-se, para nós, ao mesmo tempo, de um instrumento/meio e um fim em si próprio. O empoderamento das mulheres implica, para nós, na libertação das mulheres das amarras da opressão de gênero, da opressão patriarcal. Para as feministas latino-americanas, em especial, o objetivo maior do empoderamento das mulheres é questionar, desestabilizar e, por fim, acabar com a ordem patriarcal que sustenta a opressão de gênero. Isso não quer dizer que não queiramos também acabar com a pobreza, com as guerras, etc. Mas para nós o objetivo maior do "empoderamento" é destruir a ordem patriarcal vigente nas sociedades contemporâneas, além de assumirmos maior controle sobre "nossos corpos, nossas vidas". (SARDENBERG, 2006, p. 2)

León (2001, p. 96) também nos traz o seguinte esclarecimento sobre a questão:

Uma das contradições fundamentais do uso do termo "empoderamento" se expressa no debate entre o empoderamento individual e o coletivo. Para aqueles que o usam na perspectiva individual, com ênfase nos processos cognitivos, o empoderamento se circunscreve ao sentido que os indivíduos se autoconferem. Tomam-no num sentido de domínio e controle individual, de controle pessoal. É "fazer as coisas por si mesmo", "ter êxito sem a ajuda dos outros". Esta é uma visão individualista, que chega a assinalar como prioritários os sujeitos independentes e autônomos com um sentido de domínio de si mesmos, e desconhece as relações entre as estruturas de poder e as práticas da vida cotidiana de indivíduos e grupos, além de desconectar as pessoas do amplo contexto sociopolítico, histórico, do solidário, do que representa a cooperação e o que significa preocupar-se com o outro.

Isso significa dizer então que o discurso publicitário veiculado pela Avon acerca do empoderamento feminino é, no fim das contas, um engodo? Um mero embuste para camuflar a velha ideologia do "capitalismo libertador", do "trabalhar para vencer na vida"?

Em parte, sim. Por outro lado, a Avon vem produzindo no Brasil uma série de peças publicitárias que fogem a essa configuração do empoderamento via independência financeira - algo herdado diretamente do discurso empresarial norte-americano, como se constata no site da Avon nos Estados Unidos. ${ }^{7}$ Em particular, nos chamou atenção o comercial intitulado "Dona dessa beleza" - ou "\#DonaDessaBeleza" -, publicado

7. Disponível em: <https://goo.gl/PkG8g>. Acesso em: 28 nov. 2016. 
através da plataforma de vídeos do YouTube e nas redes sociais da Avon, em novembro de 2016, e atualmente com mais de quatro milhões de visualizações. ${ }^{8}$ Além de promover a visibilidade de mulheres com as mais variadas características e bem diferentes das modelos típicas dos anúncios de cosméticos, o filme também foi lançado em versão acessível para pessoas com deficiência auditiva e visual ${ }^{9}$ (Figura 4).

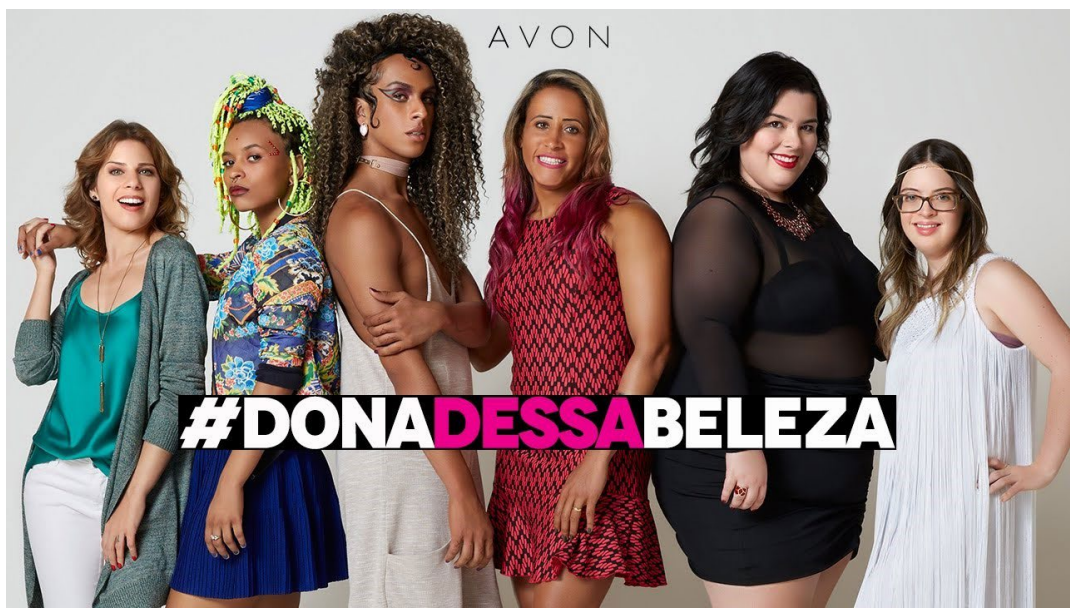

Figura 4. Filme publicitário "Dona dessa beleza”, da Avon (2016).

Fonte: Canal da Avon Brasil no YouTube.10

Vale frisar que, conforme Fairclough (2012), uma das missões da Análise Crítica do Discurso consiste em identificar não apenas os problemas relacionados a práticas sociais e culturais ("apreciação negativa”), mas também as possibilidades de resolução dos obstáculos (“apreciação positiva”). Dessa maneira, é possível observarmos que essa peça publicitária constitui um ótimo exemplo de um "ponto fora da curva", escapando da noção capitalista e individualista de empoderamento usada habitualmente pela Avon, bem como dos clichês que pululam nos comercias de perfumes e produtos de beleza femininos.

As duas seções a seguir serão dedicadas, pois, à análise dos elementos diferenciais desse comercial, sob a ótica da ACD.

\section{REGIMES DE VISIBILIDADE DO CORPO DIFERENTE NA PUBLICIDADE}

Na contemporaneidade, a temática da diferença tem-se tornado recorrente na mídia, seja na representação do fazer artístico, seja na reivindicação da práxis jornalística. Cada vez mais, nos dias de hoje, a diferença é percebida, discursivizada e instalada nos domínios midiáticos, construindo sentidos e deslocando outros tantos. Na comunicação publicitária, em especial, percebe-se que há estrategicamente uma tendência a acolher esse tema em seus discursos, adaptando-se a um panorama social favorável a convocações voltadas à aceitação da diversidade e das mais variadas identidades.

Assim, representações de corpos diferentes começam a se fazer presentes no domínio publicitário - ainda que de modo tímido - a partir

8. Disponível em: <https://goo.gl/pOrhKZ>. Acesso em: 28 nov. 2016.

9. Disponível em: <https://goo.gl/lYIddK>. Acesso em: 28 nov. 2016.

10. Disponível em: <https://goo.gl/pOrhKZ>. Acesso em: 28 nov. 2016. 
de discussões sobre preconceito, inclusão, aceitação e acessibilidade. Segundo Hoff (2012), caracterizam-se como corpos diferentes aqueles que fogem ao padrão estético naturalizado pela mídia, tais como o corpo envelhecido, o corpo obeso, o corpo doente, o corpo com deficiência etc. Essas corporeidades vêm sendo marginalizadas por décadas, sendo excluídas social e midiaticamente, e tendo o seu regime de visibilidade limitado a valores de inferioridade, como fragilidade e incapacidade.

Recentemente, contudo, o panorama midiático contemporâneo tende a fortalecer os corpos diferentes, a partir de discursos que encorajam os sujeitos a assumirem seus corpos e identidades. Sendo assim, os discursos da diferença tornam-se visíveis, principalmente no ambiente on-line, onde os chamados "influenciadores digitais" utilizam a sua própria identidade, investida e revestida de poder, a fim de desmistificar e desconstruir estigmas direcionados aos corpos diferentes. Como consequência, incentivam outros indivíduos a se aceitarem e se reconhecerem pertencentes ao meio social. Concebemos aqui o discurso da diferença como aquele que configura um convite a estéticas corporais não hegemônicas, não normativas, ou seja, aos corpos diferentes.

Retomando então o citado vídeo da campanha "Dona dessa beleza" da Avon (Figura 4), é possível notar a construção de um novo sentido para empoderamento feminino. Esse significado, cabe enfatizar, é bastante distinto do empregado nas comunicações publicitárias tradicionais da empresa - que ultimamente vem buscando, aliás, um reposicionamento de sua marca ${ }^{11}$. Isso advém de uma tendência mercadológica de as marcas se comprometerem subjetivamente cada vez mais com seu públicoalvo. Elas utilizam seu lugar de fala no espaço midiático para promover mensagens e causas que dialogam com valores socialmente responsáveis.

É nesse sentido que a Avon demonstra crescente interesse em representações sociais minoritárias e/ou marginalizadas - tanto pela mídia quanto pela sociedade - como é o caso, por exemplo, de mulheres transexuais, plus size e rappers negras. Na campanha "Dona dessa beleza", a empresa reforça seu propósito de embelezar corpos de todos os biótipos e transformar vidas, empoderando mulheres. Vale frisar novamente que o empoderamento aqui não diz mais respeito ao "narcisismo como liberação”, criticado por Tyler (2005). Antes, busca expressar a postura da Avon em favor do respeito feminino, valorizando as múltiplas faces da beleza.

A campanha foi criada e produzida pela agência Matuto, e protagonizada por um elenco inclusivo, composto por seis influenciadoras digitais: Kessidy Reis (rapper negra), MC Linn da Quebrada (transexual), Terezinha Guilhermina (com deficiência visual), Samanta Quadrado (com síndrome de Down), Bee Reis (plus size) e Pri Camomila (com deficiência auditiva). Inicialmente, as personagens são apresentadas individualmente, dançando ao som da música "Não fica na reta" da rapper Kessidy Reis, uma das personagens do anúncio. As mulheres seguem seu próprio ritmo, maquiam-se e interagem com a câmera. Transparecem confiança em suas atitudes, conforto com o próprio corpo e elevada autoestima. Ao final, as personagens se unem e dançam em conjunto, explicitando ainda mais as diferentes belezas.

11. Antes mesmo da campanha "Dona dessa beleza", a Avon já havia chamado a rapper e cantora negra Karol Conka para estrelar o comercial do rímel "Big and Define”. Disponível em: <https://goo.gl/HJQOqU>. Acesso em: 13 dez. 2016. 
O cenário mimetiza um camarim no backstage, contribuindo para a produção de uma campanha descontraída e sem demarcações de limites, permitindo ao consumidor inferir que as modelos tiveram liberdade na escolha dos seus movimentos corporais. Isto é, investiram sua personalidade no anúncio. É possível perceber ao longo do comercial que as mulheres flagrantemente diferem uma das outras e escapam ao estereótipo da modelo esquálida e "glamourosa" dos anúncios habituais de cosméticos. Algumas dançam mais expressivamente, outras de forma mais contida. Algumas se maquiam de maneira mais intensa, enquanto outras escolhem tons mais suaves de maquiagem. A marca demonstra interesse exatamente nessa multiplicidade de formas, gostos, cores, atitudes etc.

Outro aspecto que se destaca nesse filme publicitário é a trilha sonora. Além do ritmo dançante e alto-astral, a letra da música traduz o objetivo comunicacional da campanha, cuja essência é valorizar as diversas belezas através do empoderamento feminino. O rap da Kessidy Reis carrega em si um discurso de denúncia e resistência, evidenciando o direito de escolha que cada pessoa possui no que diz respeito ao seu próprio corpo, seja no modo de se vestir, seja no modo de se comportar e se relacionar. ${ }^{12}$

Um frame do comercial que conquista a atenção do público é o painel de fundo onde a rapper Kessidy dança. Nele, algumas expressões estão escritas e, em sua maioria, são frases de ordem que demarcam posicionamentos sociais com intuito de reivindicar a liberdade de cada um se manifestar. Entre as frases, algumas se destacam: "Respeita as minas”, "Deixa ela falar”, "Deixa as gordas em paz", "Visibilidade importa” e "Minha pele preta é meu manto de coragem" (Figura 5). Constata-se que são pensamentos que englobam outras reflexões tão atuais e necessárias quanto o empoderamento feminino, como a gordofobia e o racismo.

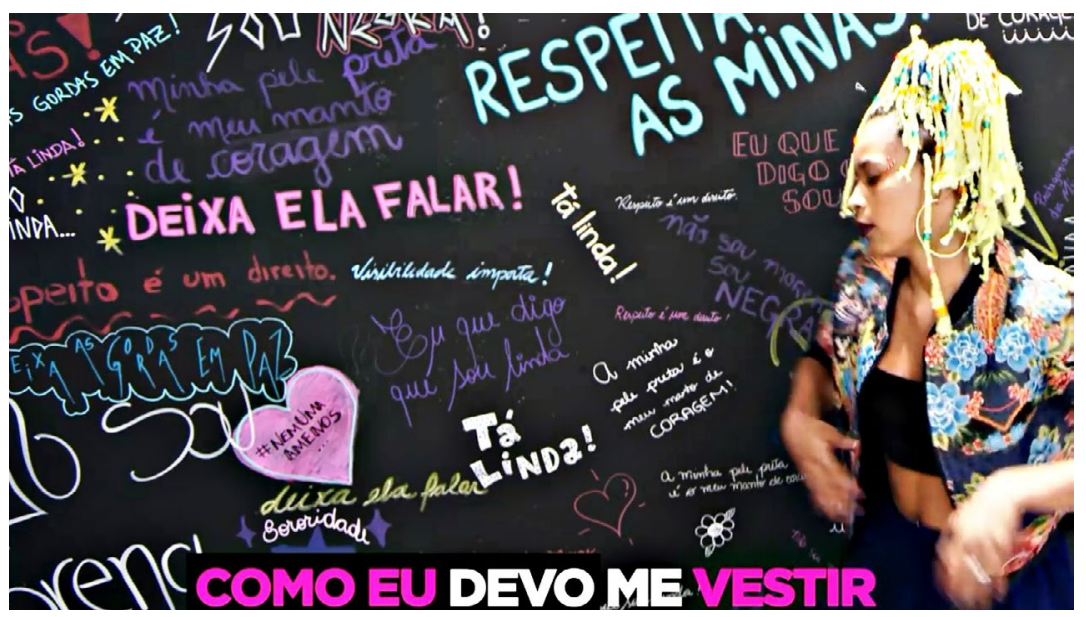

Figura 5. Frame do filme publicitário "Dona dessa beleza”, da Avon (2016).

Fonte: Canal da Avon Brasil no YouTube. ${ }^{13}$

Fica evidente, pois, que a Avon se posiciona favoravelmente à diversidade dos corpos na sociedade e a sua visibilidade midiática. Afastase, assim, da perspectiva individualista/capitalista do empoderamento como

12. "Você não tem o direito de falar como eu devo me vestir, como eu devo me portar./ Você não tem o direito de falar como eu devo, devo, nem porque eu devo, devo”.

13. Disponível em: <https://goo.gl/pOrhKZ>. Acesso em: 28 nov. 2016. 
sinônimo apenas de independência financeira, que ainda persiste em outros momentos do discurso da empresa, como vimos anteriormente. Embora seja uma ação ousada e surpreendente, a marca, na verdade, vem seguindo uma tendência da comunicação publicitária, caracterizada pelo interesse pela defesa de "causas sociais", como reflete Covaleski (2015b). Para o autor, as marcas que discursam carregando consigo valores éticos cativam o público, despertando seu interesse e conquistando sua aprovação:

Essas atitudes cujo discurso, invariavelmente, vem carregado de valores éticos têm chamado a atenção dos cidadãos, que estão ansiosos por ações que tragam resultados efetivos à sociedade. Quando isso ocorre, tornam-se adeptos das causas defendidas e admiradores das marcas que as defendem, e mais dispostos a consumir determinadas marcas por meio dos valores que elas propagam. (Ibidem, p. 4)

Esse movimento de obter a aprovação do público por meio de ações cada vez mais inclusivas se mostra ainda mais evidente na campanha "Dona dessa beleza”, pois, além de trazer representações de corpos femininos diferentes, a Avon disponibilizou uma versão acessível do filme publicitário. Nessa versão, há recursos que facilitam a compreensão do anúncio para quem possui alguma deficiência - como audiodescrição e Libras -, já que o intuito da marca é dialogar com todas as mulheres.

Em parceria com a associação Mais Diferenças - que trabalha com práticas e políticas inclusivas - a Avon deixa claro que a acessibilidade e a inclusão devem ser enaltecidas como valores que revelam e propõe outras formas de beleza. É sobre esse tema que iremos tratar a seguir.

\section{ACESSIBILIDADE E INCLUSÃO NA PUBLICIDADE}

Considerando-se que $23,9 \%$ da população brasileira possui algum tipo de deficiência, e que $18,6 \%$ desse montante é composto por pessoas com deficiência visual - maior número entre as deficiências, de acordo com o Censo de 2010 do Instituto Brasileiro de Geografia e Estatística (IBGE) -, pode-se compreender a crescente necessidade de tornar os conteúdos imagéticos acessíveis ao maior universo possível de pessoas. Isso se aplica especialmente aos conteúdos de fácil e amplo alcance massivo, como os veiculados na televisão e na internet.

Da mesma forma, há uma expectativa de que as pessoas com deficiência auditiva $-5,1 \%$ da população com deficiência - possam compreender os conteúdos falados nos canais midiáticos. Esse grupo pode ser dividido entre as pessoas que falam a língua brasileira de sinais (Libras) e aquelas que leem legendas para surdos e ensurdecidos (LSE). Os surdos congênitos ou os que ficaram surdos muito cedo geralmente falam Libras. Os ensurdecidos, que têm surdez adquirida depois da alfabetização em português ou da aquisição da fala nessa língua, e ainda os que receberam o implante coclear $^{14}$, preferem a LSE. Mas como qualquer recorte de uma população, essa generalização é apenas didática para que possamos perceber a dimensão da complexidade e da diversidade do segmento das pessoas com deficiência auditiva.

14. O implante coclear consiste em um dispositivo eletrônico, implantado parcialmente, que tem como finalidade proporcionar aos usuários uma sensação auditiva similar à fisiológica. 
Peças publicitárias com algum tipo de acessibilidade são relativamente recentes. No ramo dos cosméticos, em particular, a empresa Natura foi responsável por lançar, em 2008, o primeiro comercial veiculado na televisão com audiodescrição (AD) $)^{15} \mathrm{e} \mathrm{com} \mathrm{legendas,} \mathrm{para} \mathrm{anunciar} \mathrm{a} \mathrm{linha}$ de produtos Natura Mamãe e Bebê ${ }^{16}$. Naquela época, a notícia foi dada no site de maior acesso por pessoas com deficiência visual - o Bengala Legal ${ }^{17}$ - e comemorada como forte prova de que a audiodescrição na TV era uma realidade possível de ser praticada.

Apenas em julho de 2010 a AD teve a sua primeira exibição em um programa na televisão brasileira: o seriado mexicano Chaves, transmitido aqui pelo Sistema Brasileiro de Televisão (SBT) ${ }^{18}$. Isso ocorreu devido à Portaria $\mathrm{n}^{\circ}$ 188/2010 do Ministério das Comunicações, que entrou em vigor no dia 24 de março de $2010^{19}$, regulando a exibição da AD na TV, mas com prazo demasiadamente estendido, sob o pretexto de que era preciso formar profissionais para atender à cadeia produtiva. Essa norma instituiu um padrão de acréscimo de duas horas semanais de audiodescrição a cada dois anos. Espera-se que em 2034 tenham-se 24 horas da programação televisiva com AD. A inserção dos comerciais com audiodescrição irá preencher a lacuna silenciosa que surge entre os programas já acessíveis.

As políticas de inclusão relativas à acessibilidade comunicacional ganharam mais força com a nova Lei Brasileira de Inclusão (LBI) - Lei Federal $n^{\circ} 13.146$, datada de 6 de julho de $2015^{20}$-, tornando obrigatória a implantação das tecnologias assistivas em anúncios publicitários em qualquer veículo de comunicação (BRASIL, 2015) ${ }^{21}$. Ainda não há um recurso que permita que a Libras seja exibida individualmente na TV, o que faz com que haja resistência para a sua adoção de forma aberta. Já em relação aos conteúdos on-line, constata-se que a tendência é criar duas peças publicitárias: uma com e a outra sem as acessibilidades.

É justamente o que ocorre com a campanha "Dona dessa beleza", da Avon. Dessa forma, a fim de que possamos fazer algumas reflexões sobre esse filme publicitário, passaremos a investigar a seguir a versão com acessibilidade da peça ${ }^{22}$, levando-se em consideração as instruções do Guia para produções audiovisuais acessíveis (NAVES et al., 2016), do Ministério da Cultura e da Secretaria do Audiovisual.

Inicialmente, podemos verificar que o anúncio, além de buscar dar acesso às pessoas com deficiência visual e auditiva, as coloca em cena

15. “Audiodescrição: é a narração, em língua portuguesa, integrada ao som original da obra audiovisual, contendo descrições de sons e elementos visuais e quaisquer informações adicionais que sejam relevantes para possibilitar a melhor compreensão desta por pessoas com deficiência visual e intelectual” (BRASIL, 2006).

16. Disponível em: <https://goo.gl/XNinAo>. Acesso em 11 dez. 2016.

17. Disponível em: <https://goo.gl/OmQQIC>. Acesso em: 11 dez. 2016.

18. Disponível em: <https://goo.gl/Zv2voy>. Acesso em: 12 dez. 2016.

19. Disponível em: <https://goo.gl/Hzw67j>. Acesso em: 11 dez. 2016.

20. Disponível em: <https://goo.gl/J3cVSx>. Acesso em: 11 dez.2016.

21. O termo "tecnologias assistivas" é usado para identificar o conjunto de recursos e serviços que contribuem para proporcionar ou ampliar habilidades funcionais de pessoas com deficiência e, consequentemente, promover sua independência e inclusão social. Observese, em especial, o art. $69, \S 1^{\circ}$, da LBI.

22. Disponível em: <https://goo.gl/4YWDf6>. Acesso em: 12 dez. 2016. 
como protagonistas. Uma das personagens não só aparece como uma consumidora dos produtos Avon, mas também atua como profissional da acessibilidade durante o comercial. Isto é, trata-se de uma mulher surda que integra o elenco das modelos e sinaliza a música ao longo da peça. Essa estratégia aproxima as outras pessoas surdas, por ser uma comunicação na língua mãe, sem mediação.

Outro aspecto significativo a ser salientado é que a opção de legenda está disponível somente na versão regular do filme publicitário, que não contém audiodescrição ou Libras. Em outras palavras, os ensurdecidos assistem ao filme regular e não ao acessível. Haveria aí um deslocamento de um grupo de pessoas com deficiência que assistiria ao filme igualmente às pessoas sem deficiência. Segundo o conceito do "desenho universal" (CARLETTO; CAMBIAGHI, [200-?]), isso consiste de fato em um dado positivo, já que qualquer pessoa deveria poder acessar os mesmos ambientes e conteúdos. Na peça regular”, as legendas explicitam a letra da música; já na peça acessível, a letra fica em segundo plano para as pessoas cegas, pois o volume da trilha sonora da $\mathrm{AD}$ a encobre.

Retomando agora a postura crítica que é o norte analítico deste artigo, também podemos levantar alguns questionamentos particularmente no que diz respeito à acessibilidade. Em primeiro lugar, é possível indagarmos se a audiodescrição não poderia ter sido realizada utilizando-se uma voz feminina como narradora. Será que haveria outro impacto para as mulheres cegas ouvir uma mulher falando em vez de uma voz masculina?

Note-se que, tal como já discutimos anteriormente, o principal mote da peça é o empoderamento das mulheres. É de causar um certo estranhamento o fato de um comercial protagonizado exclusivamente por um elenco feminino ter uma voz masculina narrando frases de ordem como "se aceite", "se liberte", "seja \#DonaDessaBeleza". Soa bem contraditório que, no fim das contas, (a voz de) um homem é quem suspostamente tenha que empoderar essas mulheres, ditando-lhes como ser e como agir.

Ainda sobre a audiodescrição, também é possível criticá-la no que se refere ao relato das características físicas das personagens que integram o filme publicitário. A AD deixou de enfatizar os diferentes looks, restringindo-se a nomear as protagonistas. Novamente o narrador masculino é responsável por adjetivações no mínimo bastante subjetivas, como “dança provocante”, "linda mulher”, “belas tranças” etc. É provável que as pessoas com deficiência visual façam perguntas como: "como será essa trans?”, “o que tem a mulher cega de linda?”, “como estão vestidas?” e assim por diante.

Apesar dessas ressalvas, nunca é demais salientar a importância e a necessidade cada vez maior de iniciativas como essa da Avon. Muito mais do que mero cumprimento de uma formalidade legal, o caráter inclusivo dessa peça publicitária tem como principal mérito a naturalização da imagem de pessoas com deficiência na mídia e na sociedade, bem como a viabilização do acesso e da melhor compreensão dos conteúdos midiáticos por esses usuários.

\section{CONSIDERAÇÕES FINAIS: QUEM É A \#DONADESSABELEZA?}

$\mathrm{Na}$ contemporaneidade, a publicidade integra um complexo e importante sistema simbólico de práticas sociais e discursivas, responsável por criar e/ou manter - e, não raro, redefinir - subjetividades, afetividades 
e modelos de comportamento dos membros de uma comunidade. Nesse sentido, Covaleski (2015a, p. 64) argumenta que "permeando o cotidiano humano, as narrativas são recorrentemente empregadas pela publicidade para contar-nos histórias que nos emocionem, engajem-nos, levem-nos a experiências sensoriais variadas”.

Ao analisarmos criticamente a campanha "Dona dessa beleza" da Avon, essa constatação acerca do discurso publicitário revelou-se bastante manifesta e inequívoca. Mais do que um simples reflexo de uma realidade cada vez mais diversificada como a que vivemos, a peça é responsável por construir mundos, histórias e representações identitárias que passam longe dos clichês publicitários de produtos cosméticos (com suas modelos lânguidas, famélicas e sexys) e fazem o espectador refletir, questionar valores, se indagar, se emocionar. É praticamente impossível permanecer incólume ou indiferente diante de uma propaganda tão impactante - mas, ao mesmo tempo, simples e direta - como essa.

Buscamos então, ao longo deste artigo, mostrar o percurso traçado pela Avon até chegar a esse novo posicionamento. Partimos do momento em que a empresa tinha como principal política a valorização do esforço individual de suas revendedoras como forma de se "empoderarem" - o que era/é, na verdade, um processo de "individualização feminina" - até o momento atual, em que campanhas como a "Dona dessa beleza" têm efetivamente como propósito o reconhecimento do amplo e multifário público feminino.

Se as críticas aqui arroladas evidenciam a existência ainda de elementos contraditórios ou mesmo de decisões desacertadas no discurso publicitário, também foi possível constatarmos uma série de boas ideias e excelentes encaminhamentos no que se refere à inclusão social e ao respeito aos/ às consumidores/as. Já é um ótimo começo para prestigiar e promover a visibilidade de todas as mulheres - negras, gordas, trans, com deficiências etc. - que são, de fato, as donas dessa beleza plural e admirável.

\section{REFERÊNCIAS}

AVON chama: rádio 1970 Brasil. 0'37'. YouTube. 2016. Disponível em: <https://goo.gl/ tQbXRi>. Acesso em: 23 nov. 2016.

BRASIL. Portaria no 188, de 24 de março de 2010. Altera a redação do subitem 3.3 e do item 7 da Norma Complementar no 1/2006 - Recursos de acessibilidade, para pessoas com deficiência, na programação veiculada os serviços de radiodifusão de sons e imagens e de retransmissão da televisão, aprovada pela Portaria nํ 310, de 27 de junho de 2006 Diário Oficial da União, Brasília, DF, 28 jun. 2006.

Lei no 13.146, de 6 de julho de 2015. Institui a Lei Brasileira de Inclusão da Pessoa com Deficiência. Diário Oficial da União, Brasília, DF, 7 jul. 2015. Seção 1. p. 2.

CARLETTO, A. C.; CAMBIAGHI, S. Desenho universal: um conceito para todos. [200-?] Disponível em: <https://goo.gl/FdLqRh>. Acesso em: 12 dez. 2016.

COVALESKI, R. Narrativa como estratégia publicitária para ações de responsabilidade social e de políticas de consumo sustentável. In: COLÓQUIO NARRATIVA, MÉDIA E COGNIÇÃO, 2015, Porto. Anais... Porto: Universidade Católica Portuguesa, 2015a. p. 60-69.

Responsabilidade, solidariedade e sustentabilidade: causas sociais no Cannes Lions Innovation Festival 2015. In: CONGRESSO BRASILEIRO DE CIÊNCIAS DA COMUNICAÇÃO, 38., 2015, Rio de Janeiro. Anais eletrônicos... Rio de Janeiro: UFRJ, 2015b. Disponível em: <https://goo.gl/cRUDjl>. Acesso em: 28 nov. 2016.

DENEULIN, S.; SHAHANI, L. An introduction to the human development and capability approach: freedom and agency. Sterling: Earthscan, 2009 
FAIRCLOUGH, N. Análise Crítica do Discurso como método em pesquisa social e científica. Linha D’Água, São Paulo, n. 25, v. 2, p. 307-329, 2012.

. Discurso e mudança social. 2. ed. Trad. de Izabel Magalhães. Brasília: UnB, 2016.

HOFF, T. M. C. Produção de sentido e publicização do discurso da diferença na esfera do consumo. In: ROCHA, R. M.; CASAQUI, V. (Orgs.). Estéticas midiáticas e narrativas do consumo. Porto Alegre: Sulina, 2012. p. 145-161.

LEÓN, M. El empoderamiento de las mujeres: encuentro de primer y tercer mundos en los estudios de género. La Ventana: Revista de Estudios de Género, Guadalajara, v. 2, n. 13, p. 94-106, 2001.

MCROBBIE, A. Postfeminism and popular culture: Bridget Jones and the new gender regime. Feminist Media Studies, Thousand Oaks, v. 4, n. 3, p. 255-264, 2004.

NAVES, S. B. et al. (Orgs.). Guia para produções audiovisuais acessíveis. Brasília, DF: Ministério da Cultura, 2016. Disponível em: <https://goo.gl/1kfoiP>. Acesso em: 12 dez. 2016.

PALAVRAS para conhecer e inspirar. [20??]. Disponivel em: <https://goo.gl/bspS7h>. Acesso em: 27 nov. 2016

SARDENBERG, C. M. B. Conceituando "empoderamento" na perspectiva feminista. In: SEMINÁRIO INTERNACIONAL: TRILHAS DO EMPODERAMENTO DE MULHERES, 1., 2006, Salvador. Anais eletrônicos... Salvador: UFBA, 2006. Disponivel em: <https://goo.gl/30BbPZ>. Acesso em: 28 nov. 2016.

TRABALHO inspirador, empoderando mulheres. [20??]. Disponível em: <https://goo gl/OikvJt>. Acesso em: 26 nov. 2016.

TYLER, I. Who put the "Me" in feminism? The sexual politics of narcissism. Feminist Theory, Thousand Oaks, v. 6, n. 1, p. 25-44, Apr. 2005. 